\title{
Pink Globalization: Hello Kitty sebagai Instrumen Soft-Diplomacy Jepang
}

\author{
Najamuddin Khairur Rijal \\ Universitas Muhammadiyah Malang
}

\begin{abstract}
ABSTRAK
Pink globalization merujuk pada istilah untuk menggambarkan popularitas internasional Hello Kitty melalui penyebaran berbagai jenis produk berlabel Hello Kitty yang kawaii dari Jepang sebagai bagian dari dunia industri. Popularitas Hello Kitty tersebut merupakan soft-power yang memberikan kekuatan nasional tersendiri Jepang. Jepang kemudian menjadikan Hello Kitty sebagai instrumen soft-diplomacy sebagai upaya meningkatkan citra pariwisata dan menarik wisatawan untuk berkunjung ke Jepang. Tulisan ini mengkaji mengenai bagaimana Jepang menggunakan Hello Kitty sebagai instrumen softdiplomacy dan bagaimana produk budaya pop Jepang berupa manga dan anime dapat menjadi kekuatan nasional. Tulisan ini berpendapat bahwa penggunaan Hello Kitty secara khusus, dan berbagai produk budaya pop berupa manga dan anime secara umum, mampu meningkatkan citra pariwisata Jepang dan membangun citra positif tentang Jepang serta memberikan keuntungan ekonomi bagi Jepang yang ditandai dengan lahirnya istilah Cool Japan dan Gross National Cool.
\end{abstract}

Kata-Kata Kunci: Pink globalization, Hello Kitty, soft-diplomacy, Cool Japan

Pink globalization refers to the term used to describe the international popularity of Hello Kitty through the spreading of various products labeled kawaii Hello Kitty from Japan as part of the industrial world. The popularity of Hello Kitty is a soft-power that gives its own Japan's national power. Japan then makes Hello Kitty as an instrument of soft-diplomacy to improve tourism image and attract tourists to visit Japan. This article examines how the Japan use the Hello Kitty as an instrument of soft-diplomacy and how the Japan's pop culture products such as manga and anime can become a national power. This paper argues that the use of Hello Kitty in particular, and pop culture such as manga and anime in general, is able to improve Japan's tourism image and build a positive image of Japan as well as provide economic benefits marked of the term Cool Japan and Gross National Cool.

Keywords: Pink globalization, Hello Kitty, soft-diplomacy, Cool Japan 
Jepang adalah negara yang terkenal dengan beragam produk budaya populer (budaya pop). Ikon-ikon budaya pop Jepang tersebar ke seluruh penjuru dunia dan menjadi pendamping dari produk-produk industri Jepang. Budaya pop Jepang tersebut antara lain dalam bentuk makanan, fashion, manga dan anime. Manga (baca: man-ga atau ma-ng-ga), dalam bahasa Jepang, berarti komik. Kata itu, di luar Jepang, digunakan khusus untuk membicarakan tentang komik Jepang. Contoh manga seperti Naruto, One Piece, Detective Conan, Dragon Ball, dan lainnya. Sementara, anime tampil dalam bentuk tulisan dalam tiga karakter katakana $a$, ni, me yang merupakan bahasa serapan dari bahasa Inggris "animation" dan diucapkan sebagai "anime-shon", merujuk pada animasi khas Jepang. Anime bisa juga diartikan sebagai manga yang bergerak atau difilmkan, karena memang sebagian besar anime berawal dari manga. Tetapi, tidak semua anime awalnya merupakan manga dan tidak semua manga menjadi anime. Contoh anime adalah Hello Kitty, Doraemon, Pokemon, dan lain-lain.

Lebih lanjut, salah satu contoh budaya pop Jepang adalah anime Hello Kitty yang dikenal, dinikmati, dan digemari oleh banyak orang di berbagai negara. Hello Kitty merupakan personifikasi gadis melalui karakter kucing. ${ }^{1}$ Sejak diciptakan pertama kali pada tahun 1974, Hello Kitty telah mendunia melalui berbagai jenis produk dan benda. Menyadari hal tersebut, pemerintah Jepang kemudian menggunakan Hello Kitty sebagai instrumen soft-diplomacy untuk memperkenalkan budaya Jepang dan meningkatkan citra pariwisata negaranya. Untuk itulah, tujuan utama tulisan ini adalah ingin menjawab tentang bagaimana Jepang menggunakan Hello Kitty sebagai instrumen soft-diplomacy. Pertanyaan utama tersebut didukung dengan pertanyaan lanjutan tentang bagaimana produk budaya pop Jepang berupa manga dan anime dapat menjadi kekuatan nasional.

Signifikansi kajian adalah karena Jepang memberikan warna tersendiri dengan menggunakan Hello Kitty sebagai salah satu instrumen soft-diplomacy. Padahal Jepang memiliki banyak karakter anime terkenal lainnya, seperti Shinchan, Captain Tsubasa, Naruto, Chibi-Maruko Chan, Pokemon, Doraemon, dan lainnya. Lebih dari itu, Hello Kitty adalah karakter yang identik dengan perempuan dan warna merah muda, penggemarnya yang disebut dengan Kitty-ra umumnya adalah perempuan dari berbagai kalangan usia, mulai anak-anak, remaja,dewasa, hingga orang tua. Padahal soft-diplomacy Jepang tidak ditujukan semata-mata untuk perempuan dan target pariwisata Jepang bukan hanya wisatawan perempuan. Selain itu pula, kajian tentang penggunaan Hello Kitty sebagai instrumen soft-diplomacy belum Jepang banyak ditemukan.

Tulisan ini selanjutnya dielaborasi ke dalam beberapa pembahasan, Pertama, penulis menyajikan uraian tentang istilah pink globalization dan menunjukkan beberapa kajian yang membahas tentang bagaimana Hello Kitty bisa diterima di berbagai negara. Kedua, membahas mengenai soft-diplomacy dan citra pariwisata secara konseptual. Ketiga, menguraikan bagaimana Jepang menggunakan ikon Hello Kitty sebagai instrumen soft-diplomacy dan sebagai salah satu upaya untuk meningkatkan

1 Selama ini, sebagian besar orang utamanya penggemar Hello Kitty menganggap bahwa Hello Kitty adalah karakter kucing. Tetapi, pada 28 Agustus 2014, sebagaimana diungkap Christine R. Yano yang meneliti tentang Hello Kitty, Sanrio mengatakan bahwa Hello Kitty bukan kucing melainkan karakter seorang gadis kecil dan karena itu tidak pernah ditampilkan berjalan dengan merangkak. Lebih tepatnya, seperti dikatakan juru bicara Sanrio, Hello Kitty adalah personifikasi atau anthropomorphic atau dalam bahasa Jepang disebut gijinka (Dailymailnews.com 2014). 
citra pariwisatanya. Keempat, menyajikan bahwa Hello Kitty dan budaya pop Jepang lainnya merupakan elemen soft-power yang kemudian melahirkan apa yang disebut dengan istilah Cool Japan dan memberi dampak positif bagi citra Jepang.

\section{Pink Globalization dan Internasionalisasi Hello Kitty}

Istilah pink globalization diperkenalkan dan dipopulerkan oleh Christine $\mathrm{R}$. Yano, antropolog dari University of Hawaii. Yano dalam bukunya berjudul Pink Globalization: Hello Kitty's Trek Across the Pacific (2013) melakukan kajian terhadap perkembangan dan ekspansi Hello Kitty sebagai bagian dari apa yang disebutnya sebagai Japanese Cute-Cool. Yano menyebut popularitas internasional Hello Kitty sebagai fenomena pink globalization. Hal ini karena keberhasilan Jepang menjadikan budaya popnya, khususnya Hello Kitty, sebagai kekuatan tersendiri dan mendapat tempat di hati masyarakat di berbagai negara tidak dapat dilepaskan dari proses globalisasi yang tengah berlangsung. Sementara pink, merujuk kepada warna merah muda yang identik dengan Hello Kitty.

Lebih lanjut, pink globalization merujuk pada penyebaran berbagai jenis produk berlabel Hello Kitty yang kawaii dari Jepang sebagai bagian dari dunia industri. Kawaii sering diterjemahkan sebagai "cute" dan "childlike" dalam bahasa Inggris. Kawaii memiliki karakter yang bersifat kekanak-kanakan, yang menunjukkan sifat manis, imut-imut, menggemaskan, naif/lugu, lucu, polos, simpel, asli, lembut, lemah, dan sebagainya (Kinsella 1995 dalam Skov dan Moeran 1995). Konsep kawaii kemudian bertransformasi dalam bentuk-bentuk budaya pop Jepang seperti Hello Kitty yang terkesan lucu, imut-imut, dan menggemaskan.

Pink globalization relevan untuk menjelaskan ekspansi perusahaan-perusahaan Jepang ke pasar-pasar di luar negeri, meningkatnya distribusi produk Jepang, dan kebangkitan Japan's National Cool yang didukung oleh penyebaran anime dan manga. Melalui konsep pink globalization, Yano (2013) menunjukkan bagaimana orang-orang yang awalnya tidak mengenal Hello Kitty menjadi begitu familiar dengan ikon "kucing" yang cute tersebut. Yano (2013) juga menunjukkan bagaimana ide dan produk seperti Hello Kitty yang terkesan cute diekspor dan diadopsi di luar Jepang, melalui teknik dan strategi marketing Sanrio sebagai perusahaan pemilik lisensi Hello Kitty.

Buku setebal lebih dari 300 halaman itu menyajikan perjalanan komprehensif Kittychan dari kucing lucu nan imut yang polos dan lugu menjadi sophisticated global superstar. Hello Kitty, oleh Yano (2013), dipandang sebagai komoditas yang menjadi salah satu ikon soft power Jepang. Dalam penelitiannya, Yano (2013) melakukan wawancara tidak hanya kepada pencinta Hello Kitty, tetapi juga kepada pihak yang tidak suka atau kritis terhadap Hello Kitty. Wawancara tersebut memberikan gambaran dan pengetahuan tentang bagaimana Hello Kitty bisa sedemikian berpengaruh dan terkenal ke berbagai negara, yang secara khusus di Amerika Serikat sebagai objek kajiannya.

Lebih lanjut, sifat-sifat yang dimiliki Hello Kitty seperti cuteness, coolness, girliness, sexiness, dan quirkiness serta ketiadaan mulut (mouthlessness) justru menjadi daya tarik globalnya (Yano 2013). Daya tarik global itu mendorong konsumennya berasal 
dari beragam latar belakang budaya, usia, gender, dan etnisitas. Hasil penelitian yang disusun dalam tujuh bab itu juga menunjukkan bahwa kehadiran Hello Kitty tidak menjadi ancaman bagi budaya lain, termasuk budaya tradisional. Hello Kitty tidak menggiring atau menghasut masyarakat untuk "wanna-be Asian", seperti ikon Amerika yakni Mickey Mouse atau Barbie yang mempromosikan "wanna-be White". Atas alasan itu, soft power Jepang fokus pada komoditas cute-cool untuk meningkatkan nation-branding-nya.

Selain Yano, terdapat beberapa penelitian lain yang berusaha menjelaskan eksistensi Hello Kitty sebagai kekuatan budaya Jepang. Yu-Fen Ko (2000), salah satunya, meneliti mengenai Hello Kitty dan identitas politik Taiwan. Ko (2004) mengawali kajiannya dengan menegaskan bahwa komoditas budaya Jepang memiliki sejarah panjang di Taiwan. Fenomena tingginya komoditas Jepang yang dikonsumsi masyarakat Taiwan mendapat perhatian serius dan merupakan isu yang sensitif karena dipandang sebagai bentuk Japanisasi. Perdebatan terkait Japanisasi melalui komoditas budaya menjadi titik perhatian utama Ko, khususnya anime Hello Kitty yang sangat populer di Taiwan. Ko kemudian berusaha menjawab apa makna yang disampaikan Hello Kitty sebagai komoditas budaya; bagaimana makna tersebut dikonsumsi masyarakat Taiwan; di mana posisi Hello Kitty dalam struktur budaya; dan mengapa posisinya menjadi kontroversial karena dilekatkan sebagai bagian dari Japanisasi.

Berdasarkan elaborasi teori semiotik post-strukturalis, teori cultural studies mengenai resistensi budaya, dan teori discursive power Foucaultian, Ko menguji hubungan antara konsumsi dengan identitas kultural dalam tren globalisasi. Menurutnya, Hello Kitty adalah tanda (sign) dan makna (meaning). Ketiadaan mulut pada Hello Kitty, misalnya, mewakili hilangnya kesadaran dan identitas nasional Taiwan. Mulut adalah simbol utama yang mendefinisikan seseorang. Ketiadaan mulut menggambarkan karakter diam dan actionless, mewakili feminitas yang selalu patuh dalam diam, serta warna pink yang identik pada Hello Kitty menunjukkan stereotip perempuan yang rapuh dan lemah.

Singkatnya, Ko mencoba membangun argumen dari dua perspektif tentang simbol dan makna Hello Kitty. Pertama, bahwa Hello Kitty pada satu pihak menunjukkan politik gender yang selalu subordinat dan hal tersebut menunjukkan relasi gender di Taiwan. Kedua, Hello Kitty pada sisi lain menjadi simbol Japanisasi yang menggambarkan ketergantungan ekonomi Taiwan pada Jepang. Penelitian Ko berusaha mengungkap makna yang tersampaikan di balik karakter Hello Kitty dalam kaitannya dengan identitas Taiwan.

Selain itu, Benjamin Ng Wai-ming (2001) melakukan penelitian mengenai keranjingan Hello Kitty di Singapura. Dalam karya berjudul The Hello Kitty Craze in Singapore: A Cultural and Comparative Analysis, menurutnya, budaya pop Jepang telah menjadi bagian integral dari budaya global yang bersaingan dengan budaya Amerika, khususnya di Asia. Kehadiran anime Jepang, khususnya Hello Kitty, menunjukkan bahwa globalisasi tidak selalu berimplikasi sebagai Amerikanisasi dan homogenisasi dalam konteks Asia. Singapura adalah pusat dari konsumsi budaya pop Jepang di Asia Tenggara menunjukkan hal tersebut.

Pada awal 2000, Hello Kitty menjadi figur atau ikon yang digemari di hampir seluruh Singapura. Untuk itu, Wai-ming berusaha menganalisis dari perspektif perbandingan 
budaya mengenai keranjingan Hello Kitty di negara itu. Wai-ming mengawali dengan membandingkan alasan di balik popularitas Hello Kitty di Jepang dan Singapura. Untuk menjelaskan popularitas Hello Kitty di Jepang, Wai-ming melihatnya dari aspek budaya, ekonomi, dan alasan psikologis di balik daya tarik dan konsumsi Hello Kitty. Namun, sekalipun Hello Kitty menjadi bisnis besar di Singapura, tetapi alasan popularitas Hello Kitty di Singapura tidak sama dibanding alasan popularitas di negara asalnya. Pertama, penggemar Hello Kitty di Singapura kebanyakan adalah anak muda. Kedua, dari alasan budaya, Hello Kitty yang cute lebih menarik bagi masyarakat etnis China, dibanding Melayu dan India. Ketiga, banyak penggemar Hello Kitty di Singapura yang tidak tahu bahwa Sanrio menciptakan Hello Kitty dengan latar belakang Eropa (Inggris). Keempat, jenis atau varietas Hello Kitty yang diproduksi di dalam negeri terbatas sehingga sebagian besar diimpor dari Sanrio.

Lebih lanjut, Wai-ming membandingkan bahwa Donald Duck, Mickey Mouse atau Rambo yang merupakan produk budaya Amerika lebih cenderung menyebarkan ideologi Amerika, tetapi Hello Kitty tidak selalu. Apakah Hello Kitty merupakan simbol dari imperialisme atau kolonialisme untuk mempromosikan nilai-nilai Jepang di Asia? Bagi Wai-ming, jawabannya bisa ya dan bisa tidak. Meskipun masyarakat Singapura tahu bahwa Hello Kitty berasal dari Jepang, tapi mereka tidak menemukan "rasa" ke-Jepang-an yang sangat kuat di dalamnya. Mereka hampir tidak memahami lebih jauh tentang masyarakat Jepang dan budayanya dengan membeli produk atau menyaksikan animasi Hello Kitty. Pada titik ini, menurutnya, Hello Kitty tidak dapat dilihat sebagai alat bagi imperialisasi budaya Jepang. Meskipun demikian, generasi muda Singapura tetap memiliki pandangan positif atas Jepang melalui budaya popnya, dibanding generasi tua yang memiliki sentimen anti-Jepang atas pengalaman sejarahnya menjajah Asia Tenggara. Karena itu, sebagai "diplomat budaya", Hello Kitty juga memiliki implikasi ideologis.

Wai-ming kemudian sampai pada kesimpulan bahwa memahami Hello Kitty sebagai bagian cultural imperialism tidak sepenuhnya relevan dalam konteks Asia atau Singapura. Bahkan karena Hello Kitty menjadi tren, banyak pengusaha Singapura yang justru memperoleh keuntungan yang lebih dibanding pengusaha Jepang dari produk Hello Kitty. Artinya, mereka mencoba mengombinasikan nilai Jepang dan nilai Asia tanpa dua budaya melebur jadi satu. Sehingga, konsep yang tepat, menurut Wai-ming, untuk menjelaskan fenomena Hello Kitty adalah hibridisasi. Hello Kitty adalah produk global, tetapi bisa di-remade di berbagai negara sesuatu dengan selera lokal, ini sekaligus menunjukkan kekuatan dari produk budaya Jepang.

\section{Soft Diplomacy dan Citra Pariwisata}

Uraian di atas menggambarkan bahwa Hello Kitty menjadi elemen soft-power yang dimiliki Jepang, hal ini yang selanjutnya digunakan sebagai instrumen dalam softdiplomacy. Soft diplomacy merupakan istilah yang berkembang seiring semakin ditinggalkannya penggunaan hard power yang dimiliki oleh suatu negara untuk mencapai kepentingannya. Melalui soft diplomacy, negara berusaha untuk memikat atau mempengaruhi negara lain dan masyarakatnya dengan kebudayaan yang dimiliki dan nilai-nilai yang dianutnya dengan cara-cara yang soft secara persuasif. Karena itu, soft diplomacy merujuk kepada penggunaan kekuatan lunak (soft power) sebagai 
instrumen diplomasi dibanding hard power yang berbasis kapabilitas militer.

Konsep soft-power sendiri diperkenalkan oleh Joseph Nye untuk merujuk pada kekuatan suatu bangsa yang bersumber pada nilai, ideologi, dan kebudayaan yang kemudian ditiru atau diikuti oleh bangsa-bangsa lain (dalam Nakamura 2011). Power dalam hal ini tidak didasarkan pada kapasitas serta kapabilitas militer (hard power) atau sesuatu yang tangible, melainkan dengan dimensi yang intangible. Hard power dan soft power pada hakikatnya adalah kemampuan untuk mempengaruhi tindakan pihak lain, namun perbedaannya terletak pada cara atau instrumen yang digunakan. Hard-power dimaknai sebagai kemampuan untuk mengambil kebijakan dengan bertumpu pada kekuatan ekonomi dan militer. Sementara itu, soft-power merupakan kemampuan suatu negara untuk menjadikan negara atau orang lain sesuai dengan keinginan negara tersebut melalui kebudayaan dan ideologi yang dimilikinya.

Seiring pergeseran dan perluasan dimensi keamanan dari keamanan tradisional ke keamanan nontradisional, dewasa ini semakin banyak negara lebih mengedepankan diplomasi nonkonvensional, yakni melalui elemen soft-power seperti produk budaya, film, musik, dan lainnya untuk mencapai kepentingan nasionalnya. Implementasi soft diplomacy tersebut dianggap membutuhkan biaya yang relatif lebih murah dibanding dengan diplomasi konvensional. Dalam konteks ini, Jepang merasa yakin bahwa dengan cara tersebut akan lebih mampu meningkatkan daya tarik Jepang di luar negeri dan menarik masyarakat internasional untuk mempelajari Jepang dan berkunjung ke Jepang.

Soft power yang dimiliki Jepang adalah budaya pop berupa manga, anime, hiburan dan lainnya. Oleh karena itu, soft diplomacy Jepang terwujud dalam apa yang dikenal dengan diplomasi budaya. Diplomasi budaya merupakan bentuk diplomasi publik dengan menggunakan budaya sebagai instrumen diplomasi. Diplomasi publik sendiri merupakan bagian dari second track diplomacy. Disebut second track diplomacy, jalur kedua dalam diplomasi karena dilakukan oleh kelompok masyarakat: profesional, akademisi, atau tokoh ternama seperti artis dan seniman, bahkan masyarakat biasa. Jadi, aktor-aktor yang terlibat dalam usaha diplomasi publik tidak hanya pemerintah, tetapi melibatkan publik secara umum.

Lebih lanjut, budaya dalam konteks diplomasi budaya tidak hanya didefinisikan sebagai high culture seperti seni-budaya, tari, musik, teater, dan kesenian tradisional, tetapi juga mencakup budaya populer (Mark 2009). Definisi diplomasi budaya antara lain dikemukakan oleh Milton Cummings (2003). Cummings (2003), dalam Mark (2009, 6) mendefinisikan diplomasi budaya sebagai "the exchange of ideas, information, art and other aspects of culture among nations and their peoples in order to foster mutual understanding".

Senada dengan itu, Shizuru Saeki (2005) mendefinisikan diplomasi budaya sebagai pertukaran ide, informasi, seni dan budaya dalam mempromosikan mutual understanding antar masyarakat di negara berbeda. Menurut Alexander Bukh (2014), diplomasi budaya merujuk pada pemanfaatan simbol-simbol budaya sebagai alat atau instrumen dalam mengomunikasikan apa yang menjadi realitas. Diplomasi budaya secara umum dapat dilihat sebagai alat utama pemerintah dalam meningkatkan daya tarik negaranya terhadap negara lain (Bukh 2014). 
Diplomasi budaya dilakukan untuk membangun foundation of trust antar negara dan masyarakat di negara berbeda yang pada akhirnya dapat meningkatkan kohesivitas. Melalui diplomasi budaya, akan terbangun persepsi positif tentang suatu negara yang pada akhirnya persepsi positif tersebut dapat mendukung dalam usaha pencapaian kepentingan. Diplomasi budaya dapat dilakukan oleh berbagai aktor, baik pemerintah, agen independen dan swasta, perusahaan, lembaga non-profit, bahkan masyarakat luas (Mark 2009).

Lebihlanjut, menurutAppel(2008), diplomasibudayasecaraesensialmerupakanproses komunikasi dua arah. Hal tersebut berkaitan dengan usaha untuk mempromosikan citra negara (nation's image) dan nilai-nilai yang dimilikinya kepada masyarakat di negara lain agar dapat memahami budayanya, nilai, dan image yang dimilikinya. Oleh sebab itu, tujuan utama dari diplomasi budaya adalah untuk "memenangkan" hati masyarakat di negara lain dan mendapat respect darinya. Hasil yang diperoleh umumnya bersifat intagible dan sulit untuk diukur. Hal itu sebab diplomasi budaya memiliki tujuan jangka panjang (Appel 2008).

Dalam konteks ini, diplomasi budaya Jepang salah satunya diwujudkan melalui penggunaan ikon Hello Kitty sebagai instrumen dalam upaya membangun citra dan persepsi positif masyarakat internasional tentang Jepang. Terbentuknya citra positif selanjutnya berimplikasi pada citra pariwisata sehingga mendorong meningkatnya aktivitas wisatawan berkunjung ke Jepang. Citra positif negara maupun citra pariwisata itu terbentuk dari dimensi dan nilai-nilai budaya yang transfer Jepang, salah satunya, melalui Hello Kitty. Hal ini sejalan dengan pendapat Kiełdanowicz (2009) bahwa diplomasi budaya merupakan prinsip dasar dalam membangun image suatu negara. Image suatu negara kemudian berhubungan dengan ekonomi, ekspor, pariwisata, dan investasi langsung yang semua itu berkontribusi dalam mempromosikan negara.

Lebih lanjut, menurut Shuling Huang (2011), pariwisata internasional merupakan hubungan yang tidak terpisahkan antara produk budaya yang ditransfer oleh suatu negara dan konsumsi produk yang diterima oleh negara tersebut. Kata Huang (2011, 13), "International tourism illustrates the close relationship between cultural production in the sending countries and cultural consumption in the receiving countries." Maknanya bahwa citra pariwisata Jepang tidak dapat dilepaskan dari produk budayanya yang dikonsumsi oleh masyarakat internasional. Dengan mengonsumsi produk budaya Jepang, dalam hal ini Hello Kitty, secara tersirat memberikan pengetahuan atau informasi terkait budaya dan nilai-nilai masyarakat Jepang yang selanjutnya berkontribusi terhadap pembangunan citra negara.

Menurut Rudy (2005), pembangunan citra suatu negara tidak hanya dimaksudkan untuk membangun citra dari kesan yang negatif menjadi positif. Namun dapat pula berarti untuk memelihara atau mempertahankan citra, hingga meningkatkan citra positif yang telah dimiliki oleh suatu bangsa. Menurutnya, citra positif adalah hal yang penting bagi suatu negara, karena citra yang dimilikinya negara tersebut akan dihormati, dihargai, disegani, dan dipercaya sehingga meningkatkan kerja sama dengan negara-negara lain dan mudah mencapai kepentingan nasionalnya di suatu negara. 


\section{Soft-Diplomacy Jepang melalui Hello Kitty}

Penggunaan Hello Kitty sebagai instrumen soft-diplomacy dibuktikan dengan ditunjuknya karakter Hello Kitty sebagai Japan Tourism Ambassador pada Mei 2008. Alasan mendasar dari penunjukan Hello Kitty tersebut adalah karena karakter anime tersebut telah dikenal di seluruh dunia dan dianggap mampu mewakili karakter budaya Jepang di mata dunia. "Hello Kitty, Japan's ubiquitous ambassador of cute, has built up an impressive resume over the years. Global marketing phenom. Fashion diva. Pop culture icon. Now the moonfaced feline can add 'government envoy' to the list," tulis surat kabar NBC sebagaimana dikutip dari kantor berita The Associated Press (AP) (nbcnews.com 2008).

Harian terkemuka di Inggris bahkan menulis bahwa penunjukan Hello Kitty sebagai tourism ambassador Jepang adalah merupakan yang pertama kalinya sebuah karakter kartun mengambil peran yang selama ini dilakukan manusia. "It is the first time a cartoon character has taken on the normally human role," tulisnya (metro. co.uk 2008). Hello Kitty dipandang menjadi a global phenomenon yang diminati oleh banyak orang di seluruh dunia. Produk-produk bertema Hello Kitty bahkan mencapai lebih dari lima puluh ribu jenis yang tersebar dan dijual di lebih dari 6o negara (metro. co.uk 2008).

Menteri Infrastruktur, Perhubungan, dan Pariwisata Jepang Tetsuzo Fuyushiba menunjuk Hello Kitty sebagai duta pariwisata guna mempromosikan Jepang dan mengundang banyak wisatawan, terutama dari China dan Hong Kong. Hello Kitty sebagai duta pariwisata bertugas untuk mempromosikan berbagai wilayah yang menjadi tujuan wisata di Jepang. Penunjukan itu dilakukan dalam upaya Jepang mengampanyekan program Visit Japan. Misi Visit Japan merupakan tekad untuk menarik sepuluh juta wisatawan mancanegara ke Jepang setiap tahunnya. Adapun tahun 2008, ketika itu, China dan Hong Kong diharapkan akan menjadi negara dengan wisatawan terbanyak kedua setelah Korea Selatan. Wisatawan dari China dan Hong Kong yang berkunjung ke Jepang pada tahun 2007 tercatat sebesar 16,5 persen dari 8,35 juta wisatawan (nbcnews.com 2008). Angka tersebut mengalami peningkatan sebesar 60 persen sejak tahun 2003.

Tugas Hello Kitty sebagai duta pariwisata ditanggapi Presiden Sanrio Co. Ltd., perusahaan pemilik lisensi Hello Kitty, Shintaro Tsuji sebagai sebuah kehormatan (a honor). Pihaknya berjanji untuk bekerja keras menarik minat banyak wisatawan mancanegara melalui karakter Hello Kitty (nbcnews.com 2008b). Sebagai realisasinya, Hello Kitty mengadakan pertunjukan musikal yang bertema Hello Kitty's Dream Light Fantasy di Beijing, juga di Malaysia, Singapura, dan Amerika Serikat, serta berbagai cara dan upaya lain.

Sebelumnya, Hello Kitty telah menjadi karakter internasional yang tidak hanya populer di Jepang tetapi juga melanglang buana ke berbagai negara. Lembaga internasional United Nations Children's Fund (UNICEF) pada tahun 2004 pernah mengangkat Hello Kitty sebagai "Special Child Friend." Hello Kitty juga berhasil mengumpulkan dana sebesar 150.000 dolar untuk program pendidikan perempuan UNICEF (huffingtonpost.com 2008). Selain itu, Hello Kitty pernah dua kali menerima jabatan sebagai duta UNICEF. Pertama pada tahun 1983 sebagai UNICEF America Junior Ambassador dan yang kedua pada tahun 1994. 
Lebih lanjut, pada 3 September 2012, pemerintah Jepang melalui Japan Tourism Agency (JTA) dan Japan National Tourism Organization (JNTO) memperkenalkan "Visit Japan with Hello Kitty." "Visit Japan with Hello Kitty" adalah aplikasi iPhone yang berfungsi sebagai petunjuk (guide) wisata Jepang di mana Hello Kitty tampil sebagai ikon. Aplikasi tersebut memiliki fitur yang menyediakan 53 karakter Hello Kitty yang sudah berdandan dengan 47 kostum khas daerah-daerah Jepang (prefectures) seperti Hokkaido, Tokyo, Kanagawa, Osaka, Kyoto, dan lainnya (seejapan.co.uk 2012). Hello Kitty akan bertindak sebagai tour guide yang memberikan berbagai informasi terkait wilayah atau objek wisata yang dikunjungi.

Selain itu, jika wisatawan mengambil foto menggunakan kamera iPhone, maka karakter Hello Kitty dengan kostum khas akan muncul secara otomatis pada hasil foto. Foto tersebut bisa langsung di-upload ke berbagai jejaring sosial. "This is the first of a series of campaigns Japan Tourism Agency intends to undertake in cooperation with Japanese brands to promote tourism to Japan. Future campaigns are planned in collaboration with Japanese cosmetics companies and restaurants," sebagaimana ditulis situs JNTO (jnto.org.au 2012).

Usaha pemerintah Jepang untuk meningkatkan citra pariwisata Jepang tersebut setidaknya menunjukkan tren positif. Hal itu dibuktikan dari data yang setiap tahun dirilis oleh United Nations World Tourism Organization (UNWTO). Pada tahun 2013, kunjungan wisatawan mancanegara ke Jepang mencapai 10,364 juta orang (tourlib. net 2013, jnto.org.au 2014). Angka itu meningkat dibanding lima tahun sebelumnya, yakni tahun 2008 yang mencapai 8,354 juta orang. Sepuluh negara dengan jumlah wisatawan terbesar adalah Korea Selatan, Taiwan, China, Amerika Serikat, Hong Kong, Thailand, Australia, Inggris Raya, Singapura dan Malaysia. Adapun Indonesia menempati urutan kesebelas dari seluruh jumlah kunjungan wisatawan mancanegara di Jepang.

Data dan fakta yang diterangkan di atas menunjukkan bahwa Jepang dapat dikatakan berhasil menggunakan budaya popnya, dalam hal ini anime Hello Kitty, sebagai instrumen soft-diplomacy. Sebagaimana diterangkan sebelumnya, soft diplomacy merupakan istilah yang berkembang sebagai bentuk diplomasi budaya seiring semakin ditinggalkannya penggunaan hard power yang dimiliki oleh suatu negara untuk mencapai kepentingannya. Melalui soft diplomacy, negara berusaha untuk memikat atau mempengaruhi negara lain sekaligus masyarakatnya dengan kebudayaan yang dimiliki dan nilai-nilai yang dianutnya. Melalui soft diplomacy, Jepang berusaha untuk memikat atau mempengaruhi masyarakat internasional untuk berkunjung ke Jepang melalui soft power yang dimilikinya berupa anime dan manga, salah satunya yakni ikon Hello Kitty.

\section{Soft Power dan Cool Japan}

Mantan Menteri Luar Negeri Jepang Taro Aso pernah menyampaikan bahwa salah satu dari potensi soft-power Jepang adalah anime, manga, dan bentuk hiburan lain, seperti film dan gaya hidup (Effendi 2011). Situs Ministry of Foreign Affairs (MOFA) Jepang juga menulis, "The Ministry of Foreign Affairs, aiming to further the understanding and trust of Japan, is using pop-culture, .. . as its primary tools for cultural diplomacy ... pop-culture, such as Manga and Anime, has been popular 
worldwide in recent years (mofa.go.jp 2014). Aso juga pernah berbicara tentang psychological infrastructure dari diplomasi Jepang. Maksud dari psychological infrastructure adalah Jepang berusaha menggunakan pendekatan psikologis dalam diplomasinya untuk mendapatkan kesan positif dan menarik perhatian masyarakat di negara lain, tidak hanya untuk mempelajari Jepang tetapi juga datang ke Jepang (Effendi 2011).

Lebih lanjut, Kazuo Orgura (2009) dalam Japan Cultural Diplomacy menyatakan bahwa diplomasi dengan memanfaatkan instrumen soft power telah dilakukan Jepang sejak kalah Perang Dunia II. Pada saat itu, selain memperkuat perekonomian Jepang yang sedang jatuh, Jepang juga perlahan mulai mengubah persepsi tentang negaranya menjadi negara yang cinta damai kepada seluruh dunia melalui budaya tradisionalnya seperti ikebana dan upacara minum teh. Ikebana adalah seni merangkai bunga yang mewakili sifat damai dan tenang. Pada saat yang sama, Jepang mengurangi promosi budaya yang bersifat keras seperti samurai, bushido, dan harakiri.

Implementasi soft-diplomacy tersebut dianggap membutuhkan biaya yang relatif lebih murah dibanding dengan diplomasi konvensional. Jepang merasa yakin bahwa dengan cara tersebut akan lebih mampu meningkatkan daya tarik Jepang ke luar negeri dan menarik masyarakat internasional untuk mempelajari Jepang dan berkunjung ke Jepang. Hal itu terangkum dalam pernyataan (mantan) Perdana Menteri Jepang Junichiro Koizumi “. . . such efforts (cultural diplomacy) will improve recognition of Japan abroad ...” (Hayashi 2014).

Penggunaan Hello Kitty, atau secara umum budaya pop, sebagai instrumen diplomasi Jepang selanjutnya dikenal dengan Cool Japan. Istilah Cool Japan diinspirasi dari ide Douglas McGray dalam artikelnya di Foreign Policy pada tahun 2002. McGray (2002) menyebut budaya pop Jepang sebagai Japan's Gross National Cool. Menurutnya, Jepang memiliki budaya sebagai instrumen yang sangat potensial. Popularitas budaya pop Jepang yang begitu tinggi memberikan kontribusi yang besar dalam membangun citra negaranya menjadi lebih positif. McGray bahkan menyebutkan bahwa Jepang mencapai posisi sebagai a cultural super power.

Menurut McGray (2002), budaya pop Jepang berbeda dengan globalisasi McDonald dari Amerika Serikat. Budaya pop Jepang memiliki karakter khusus dan unik serta lebih independen, yang berbeda dengan produk Barat yang lebih tergantung pada jaringan perusahaan dan negara-negara. Artinya, budaya pop Jepang memiliki jalan sendiri dalam penyebarannya melalui globalisasi. Oleh karena itu, budaya pop Jepang dipandang sebagai komoditas atau produk yang memberikan keuntungan bagi Jepang. Lebih lanjut, McGray (2002) menyebut budaya pop Jepang sebagai Gross National Cool (GNC), yaitu sesuatu yang seperti Gross National Products (GNP) namun berdasar pada produk-produk budaya pop. Atas dasar itu, McGray (2002) mengatakan bahwa, "Japan is reinventing superpower again. . . Japan's global cultural influence has only grown ... Japan has far greater cultural influence now than it did in the 1980 , when it was an economic superpower."

Budaya pop Jepang sebagai kekuatan nasional Jepang dikonfirmasi oleh penelitian Tonny Dian Efendi (2011). Menurutnya, ada dua alasan utama mengapa menjadi penting bagi Jepang untuk melakukan diplomasi publik melalui instrumen soft-power yang dimilikinya. Pertama, karena munculnya persaingan antarnegara maju untuk 
membangun soft power mereka dalam menarik perhatian dan mendapatkan citra positif. Kedua adalah karena meningkatnya kekuatan China dan India yang sejalan dengan menurunnya kekuatan Jepang di negara lain. Atas alasan itu, Effendi (2011) memandang penting perlunya Jepang menyebarkan keunikan, nilai, dan budayanya.

Lebih lanjut, masih menurut Effendi (2011), berkembangnya manga dan anime ke seluruh dunia tidak hanya membawa dampak secara ekonomi, namun juga digunakan sebagai instrumen diplomasi. Hal itu dicontohkan dengan penggunaan ikon Doraemon sebagai duta animasi, Hello Kitty sebagai duta pariwisata, dan Astro Boy sebagai ikon kampanye Jepang untuk tuan rumah Piala Dunia 2022. Hasilnya adalah meningkatnya ketertarikan terhadap Jepang yang ditandai dengan meningkatkan minat anak muda di beberapa negara Asia Tenggara untuk belajar bahasa Jepang.

Dalam konteks yang sama, Hiroshi Aoyagi (t.t.) dalam penelitian bertajuk Prospects on the Impact of Cool Japan in Southeast Asia menulis tentang peran yang dimainkan oleh budaya pop Jepang di Asia Tenggara ketika pemerintah Jepang berusaha memperkuat ikatan dan relasi budaya Jepang dengan negara-negara ASEAN. Menurut Aoyagi, terjadi persaingan di arena ASEAN, baik secara ekonomi maupun budaya, yang melibatkan Jepang dengan J-wave, China dengan C-wave, dan Korea Selatan dengan K-wave yang berusaha mengonstruksikan lifestyle-nya. Keunggulan Jepang adalah apa yang disebut sebagai Japan Cool, sebagai instrumen diplomasi berbasis soft power. Implikasi Japan Cool dapat mendorong koeksistensi, komunikasi, dan kerja sama antara berbagai negara di Asia Tenggara. Lebih dari itu, diplomasi dengan instrumen kawaii, yakni menggunakan anime dan manga yang cute, menjadi penting dalam mendapatkan "hati" masyarakat Asia Tenggara. Hal di atas selanjutnya memberikan citra yang baik bagi Jepang (Otmazgin, 2012).

Selain itu, berdasarkan survei Otmazgin (2012) yang dilakukan terhadap sejumlah mahasiswa di Hong Kong, Bangkok, dan Seoul menunjukkan bahwa budaya pop telah mengubah image Jepang tidak hanya sebagai negara ex-militaristic aggresor, tetapi juga sebagai negara berkembang yang mengalami perkembangan budaya dan lifestyle yang mengagumkan di era kontemporer. Namun sekalipun begitu, dominasi budaya pop Jepang tidak dipandang sebagai bagian dari imperialisme budaya. Kekuatan daya tarik budaya Jepang adalah karena tidak bersifat nasionalis (non-nationalistic), tetapi lebih merefleksikan sisi positif dan keramah-tamahan. Secara teoritis, hasil temuan tersebut mendukung argumen bahwa budaya pop berpotensi membentuk persepsi atau citra terhadap suatu negara dari kaca mata negara lain.

Sebagai contoh, survei kepada remaja berusia antara 18-25 tahun di Amerika Serikat yang dilakukan Manion (2005) menemukan bahwa komunitas pencinta anime sangat ingin belajar tentang Jepang dan mereka antusias untuk menemukan cara agar dapat berinteraksi dengan budaya Jepang. Manion juga menemukan bahwa pelajar program bahasa Jepang lebih memahami tentang Jepang dari anime dan budaya pop Jepang lain. Singkatnya, menurut Manion, anime mengandung dan memuat unsurunsur tentang budaya Jepang yang kemudian berperan signifikan dalam membentuk pemahaman remaja Amerika tentang karakteristik budaya dan masyarakat Jepang.

Sementara itu, Hao Xiaoming dan Teh Leng Leng (2004) melakukan survei terhadap 620 pelajar Singapura untuk mengeksplorasi pengaruh budaya pop Jepang terhadap persepsi responden terhadap Jepang melalui informasi di media dan keinginan atau 
hasrat untuk memiliki barang-barang produk Jepang. Hasil yang ditemukan adalah bahwa responden aktif mengonsumsi budaya pop Jepang, seperti mendengarkan musik Jepang, membaca komik Jepang, menonton animasi Jepang, bermain game Jepang, memakan makanan Jepang, dan lainnya. Konsumsi produk-produk Jepang tersebut selanjutnya mempengaruhi persepsi dan stereotip responden terhadap Jepang.

Uraian di atas didukung oleh kesimpulan Benjamin Ng Wai-ming (2002). Menurutnya, Jepang adalah manga superpower. Jepang mampu menggeser Amerika Serikat sebagai pengekspor komik dan animasi terbesar. Popularitas komik dan animasi Jepang di Asia bahkan telah berpengaruh sejak tahun 1980-an hingga sekarang. Pengaruhnya dapat dilihat dengan banyaknya negara-negara Asia yang mengembangkan komik dan animasi yang berusaha berbeda dengan Jepang. Pengusaha-pengusaha di banyak negara Asia juga menggunakan karakter anime atau manga Jepang pada produk mereka. Dampaknya adalah animasi dan manga tersebut berperan dalam mengubah persepsi remaja terhadap Jepang.

Pengaruhnya di Hong Kong dapat dilihat dari produk-produk animasinya yang banyak belajar dan diinspirasi dari Jepang, apalagi Hong Kong terbilang pendatang baru dalam dunia animasi. Namun, dalam hal komik, Hong Kong memiliki komik tradisional sendiri yang telah lama dinikmati masyarakatnya. Dalam perkembangannya, generasigenerasi berikutnya banyak dipengaruhi oleh komik Jepang. Sementara di Taiwan, banyak komik yang men-copy style komik Jepang, begitu pula dengan dunia animasi.

Sebagai perbandingan, Wai-ming melihat hal serupa di China, Singapura, dan Korea. Komik dan animasi Jepang di China sangat terkenal dan berpengaruh pada generasi muda dan konsumen. Begitu pula dengan apa yang terjadi di Korea dan Singapura, serta Malaysia dan Thailand yang mana komik dan animasinya banyak dipengaruhi dari Jepang, bahkan dalam dunia industri hiburan dan budaya pop. Wai-ming kemudian sampai pada kesimpulan bahwa pengaruh kuat komik dan animasi Jepang di banyak negara Asia tampak seperti flying goose theory (teori atau model angsa terbang). Dalam hal ini, Jepang menjadi leader, kemudian Taiwan, Hong Kong dan Korea di barisan kedua. Adapun China dan beberapa negara-negara Asia Tenggara berada pada barisan ketiga.

\section{Simpulan}

Jepang menggunakan Hello Kitty sebagai salah satu instrumen soft diplomacy karena karakter Hello Kitty memiliki popularitas internasional. Eksistensi Hello Kitty sebagai produk budaya pop Jepang diterima, digemari dan dinikmati oleh masyarakat internasional. Hal itu ditandai dengan banyaknya produk atau barang yang diproduksi oleh berbagai perusahaan di berbagai negara dengan menggunakan ikon Hello Kitty sebagai brand. Popularitas global Hello Kitty kemudian dikenal dengan istilah pink globalization. Hello Kitty diterima selain karena memiliki sifat-sifat yang kawaii, juga karena eksistensinya tidak menjadi ancaman bagi budaya lain sebab tidak menggiring konsumennya untuk "wanna-be Asian" atau "wanna-be Japan". Hal ini berbeda dengan ikon Amerika seperti Barbie yang mempromosikan "wanna-be White". 
Penggunaan Hello Kitty tersebut selanjutnya mampu meningkatkan citra pariwisata Jepang sekaligus membangun citra positif tentang Jepang. Hal ini menunjukkan bahwa Jepang mampu memanfaatkan produk budaya popnya terutama manga dan anime sebagai sebuah kekuatan dalam bentuk soft-power. Pemanfaatan produk budaya pop tersebut tidak hanya memberikan keuntungan ekonomi bagi Jepang, tetapi juga keuntungan politis dan ideologis. Melalui soft-power dalam bentuk anime dan manga, salah satunya Hello Kitty, Jepang mampu mengubah persepsi masyarakat internasional dari citra sebagai negara agresif menjadi lebih positif. Hal itu selanjutnya menciptakan branding bagi Jepang dengan istilah Cool Japan.

\section{Daftar Pustaka}

\section{Buku dan Artikel dalam Buku}

Cummings, Milton C., 2003. Cultural Diplomacy and the United States Government: A Survey. Washington DC: Centre for Arts and Culture.

Effendi, Tonny Dian, 2011. Diplomasi Publik Jepang: Perkembangan dan Tantangan. Bogor: Ghalia Indonesia.

Kinsella, Sharon, 1995. "Cuties in Japan", dalam Skov, Lise dan Brian Moeran (eds.), 1995. Women, Media, and Consumption in Japan. Honolulu: University of Hawaii Press.

Ko, Yu-Fen, 2000. Hello Kitty and the Identity Politics in Taiwan. Taipei: Department Public Communication Hsih-Shin University.

Rudy, Teuku May, 2005. Komunikasi dan Hubungan Masyarakat Internasional. Bandung: Refika Aditama

Yano, Christine R, 2013. Pink Globalization: Hello Kitty's Trek Across the Pacific. US: Duke University Press.

\section{Artikel Jurnal}

Bukh, Alexander, 2014, "Revisiting Japan's Cultural Diplomacy: A Critique of the Agent-Level Approach to Japan's Soft Power”, Asian Perspective 38 (2014): 461485 .

Huang, Shuling, 2011. "Nation-Branding and Transnational Consumption: JapanMania and the Korean Wave in Taiwan," Media, Culture \& Society 33(1):3-18.

Ng, Benjamin Wai-ming, 2001. "The Hello Kitty Craze in Singapore: A Cultural and Comparative Analysis.” Asian Profile 29:6 (Asian Research SeRvice, Canada) Desember 2001: 481-492.

Saeki, Shizuru, 2005. "The Perry Centennial Celebration: a Case Study in US-Japanese Cultural Diplomacy", International Social Science Review, 8o(3\&4): 137-138.

Wai-ming, Benjamin Ng, 2002. "The Impact of Japanese Comics and Animation in Asia," Journal of Japanese Trade and Industry: July/August 2002:1-4.

Xiaoming, Hao dan Teh Leng Leng, 2004. "The Impact of Japanese Popular Culture on the Singaporean Youth," Keio Communication Review, 26, 2004: 17-26.

\section{Working Paper}

Mark, Simon, 2009. "A Greater Role for Cultural Diplomacy," Discussion Paper in Diplomacy Netherlands Institute of International Relations 'Clingendael', April. 
Nakamura, Toshiya, 2011. "Soft-Power and Public Diplomacy: How Cool Japan Will Be?," paper presented to the International Studies Association-Asia Pacific Regional Section Inaugural Conference 2011, Brisbane.

\section{Artikel Online}

Aoyagi, Hiroshi, t.t. "Prospect on the Impact of Cool Japan in the Southeast Asia' [online]. dalam http://www.a-jrc.jp/docs/HiroshiAoyagi.pdf [diakses 19 September 2014].

Appel, Ronit, et al., 2008. Cultural Diplomacy: An Important but Neglected Tool in Promoting Israel's Public Image. Lauder School of Government, Diplomacy and Strategy. dalam http://portal.idc.ac.il/sitecollectiondocuments/cultural_ diplomacy.pdf [diakses 29 September 2014].

Hayashi, Tai, 2004. "Japan Pushing Cultural Diplomacy" [online]. dalam http:// media.leeds.ac.uk/papers/vpo1acbe.html [diakses 17 September 2014].

Huffington Post, 2008. "Hello Kitty: Japan's Tourism Ambassador" [online]. dalam http://www.huffingtonpost.com/2008/05/20/hello-kitty-japanstouris_n_102736.html [diakses 14 September 2014].

JNTO, 2012. "Visit Japan with Hello Kitty" [online]. dalam http://jnto.org.au/visitjapan-with-hello-kitty/ [diakses 14 September 2014].

JNTO, 2014. “Tourism Data Visitor Trends 2003-2014" [online]. dalam http://www. jnto.go.jp/jpn/reference/tourism_data/visitor_trends/pdf/2003_14_tourists. pdf [diakses 17 September 2014].

McGray, Douglas, 2002. "Japan's Gross National Cool” [online]. dalam http://www. foreignpolicy.com/articles/2002/05/01/japans_gross_national_cool [diakses 17 September 2014].

Metro Newa, 2008. "Hello Kitty Becomes JapaneseAmbassador" [online]. dalam http:// metro.co.uk/2008/05/19/hello-kitty-becomes-japanese-ambassador-145087/ [diakses 14 September 2014].

Minister of Foreign Affairs, 2014. "Pop-culture Diplomacy" [online] dalam http:// www.mofa.go.jp/policy/culture/exchange/pop/index.html [diakses 17 September 2014].

NBC News, 2008. "Hello Kitty Named Japan Tourism Ambassador" [online]. dalam http://www.nbcnews.com/id/24708771/ns/travel-news/t/hello-kitty-namedjapan-tourism-ambassador/\#.VBUIcUAgtqg [diakses 14 September 2014].

Ryniejska-Kiełdanowicz, Marta, 2009. Cultural Diplomacy as a Form of International Communication. Institute for Public Relations BledCom Special Prize. dalam http://www.instituteforpr.org/wp-content/uploads/Ryniejska_Kieldanowicz.pdf [diakses 29 September 2014].

See Japan, 2012. “Japan Releases Hello Kitty Tourism App” [online]. dalam http:// www.seejapan.co.uk/jnto_consumer/media/press-releases/press-releasedetail/12-09-03/japan-releases-hello-kitty-tourism-app [diakses 14 September 2014].

Tourlib, 2013. "UNWTO Barometer 2011-2013" [online]. dalam http://tourlib.net/ wto/UNWTO_Barometer_2011_06.pdf [diakses 17 September 2014].

Manion, Annie, 2005. "Discovering Japan: Anime and Learning Japanese Culture" [online]. dalam http://www.chanpon.org/archive/manionthesis.pdf [diakses 19 September 2014].

Daily Mail News, 2014. "Hello Kitty is Actually Not a Cat" [online]. dalam http://www. dailymailnews.com/2014/o8/30/showbiz/3.php [diakses 14 September 2014]. 